\title{
Suture material use and procurement: an audit of a public hospital surgical system in Gauteng, South Africa
}

\author{
B Puttergill, D Kruger, M Brand, M G Veller \\ Department of Surgery, University of the Witwatersrand, Johannesburg, South Africa
}

Corresponding author: B Puttergill (brookeputtergill@hotmail.com)

\begin{abstract}
Introduction: Surgical systems are integral to successful, safe and cost effective clinical practice and must balance surgical demands on consumable items and their costs. Suture material is a key consumable resource, and was evaluated in an audit of consumable use and cost as well as the procurement systems within the South African Gauteng public health care sector. Aims: To determine suture use and cost in the four commonest general surgical procedures - abdominal wall closure, mastectomy, appendicectomy and inguinal hernia repair - in three academic Gauteng hospitals. Performance and availability were evaluated as a secondary aim in suture material use.

Methods: A prospective observational study. Suture use was documented by the surgeon at the time of the procedure and qualitative investigation at relevant hospital departments determined suture material procurement and expenditure.

Results: The surgeons in three facilities documented consistent material type and average number of units used; however, in some cases there was a lack of availability of appropriate material and breakage of generic material intraoperatively. There is no consistent and consolidated electronic record-keeping of suture stock and cost in all three hospitals, therefore cost of suture material used was not obtainable.

Conclusion: Clinical deficiencies in availability and quality of material may have adverse implications for patient health, healthcare costs and budgets through procedure-related complications and should be investigated. There is a lack of communication between the financial management, procurement officers, hospital and theatre stores and theatre staff. It is suggested that clinical protocols and system-based strategies be put in place to manage surgical consumables.
\end{abstract}

\section{Introduction}

Quality of medical care has been defined as 'the degree to which health services for individuals and populations increase the likelihood of desired health outcomes'. ${ }^{1,2}$ To this end the Lancet Commission on Global Surgery and World Health Organisation (WHO) surgical service guidelines recognise that efficient, cost effective systems and clinical protocols are important if improved surgical access and care is to be achieved in developing countries. ${ }^{3,4}$ One aspect of this strategy is to improve resource management through the development of cost containment procurement systems without compromising clinical standards, a relevant factor in South Africa's financial and resource constrained public healthcare sector.

One such system is the efficient provision of surgical consumables that meet clinical demands and international product standards. Suture material has been integral to procedural surgical practice for more than 5000 years, ${ }^{5}$ consequently it is an essential consumable. Despite numerous studies evaluating various suture material types, no standardised procedure-specific material has been defined as the studies were unable to control for disease-, patient- and care-dependant variables. Consequently suture material use is usually empiric, based on habit and personal preference..$^{5-8}$ Hence a wide variety of suture material must be on hand in an operating facility to accommodate a diverse range of requests by individual surgeons. These varieties and quantities of suture materials may not be cost-effective and unwieldy to manage.

Furthermore, a lack of effective procurement systems governing the provision of stock to surgical departments as well as protocols for use of these consumables may hinder improvement of hospital systems and clinical outcomes. To date, no South African study has investigated surgical consumable resources and the system that governs the provision, cost and clinical use thereof in public hospitals. The primary aims of this study were to evaluate the use of suture 
material as a surrogate of surgical consumables at a clinical level, and the cost through understanding management and procurement processes of this resource for common general surgical procedures in three Gauteng academic hospitals. Secondary aims under suture use included data variables on quality, brand, satisfaction and availability as it was necessary to determine if actual use accurately represented the surgeon's procedural demands.

\section{Methods}

A prospective observational study with Ethics clearance (M111127) was undertaken to determine two primary outcomes of suture use in the four commonest surgical procedures performed by registrars in training in South Africa ${ }^{9}$ and the annual cost of suture materials to the facility. The four procedures were abdominal wall closure at laparotomy, mastectomy, appendicectomy and inguinal hernia repair. Suture use was determined by the type and number of units of suture material used in these procedures. Use was compared between facilities through a quantitative audit process. Cost was determined through a series of interviews with the head financial and procurement officers together with data provided by these departments.

The study sites were 3 academic facilities within the public health care sector of Gauteng, hereafter referred to as hospital 1, 2 and $3(\mathrm{H} 1-\mathrm{H} 3)$. No studies were found in the literature detailing protocol development in institutions following evaluation of suture use during procedures; therefore, the power of the study was determined by using clinical studies that evaluated clinical outcomes based on suture use during surgical procedures..$^{10} \mathrm{~A}$ total of 240 procedures were included.

A convenience sample of surgeons were invited to complete a questionnaire following completion of one of the four procedures. Information included hospital name, procedure, suture material type, needle type, suture size, brand, quantity used and user satisfaction. Satisfaction was defined by the availability or non-availability of the first choice of suture material and whether or not it broke during use. Cost involved collection of procurement data through qualitative investigation and quantitative data collection. Senior management were interviewed in the procurement, finance, hospital and theatre stock departments at each hospital. Data collection was completed over a 12-month period during 2012-2013.

Table 1. Suture material use

\begin{tabular}{|c|c|c|c|c|c|}
\hline \multirow[t]{2}{*}{ Procedure } & \multirow[t]{2}{*}{ Suture Material } & \multicolumn{4}{|c|}{ Number of procedures $\&$ suture material } \\
\hline & & Total & H 1 & $\mathbf{H 2}$ & H 3 \\
\hline \multirow[t]{6}{*}{ Abdominal Wall Closure } & Number of Procedures & 60 & 20 & 20 & 20 \\
\hline & Number of suture materials & 83 & 27 & 29 & 27 \\
\hline & Polydiaxone Looped & 38 & 11 & 16 & 11 \\
\hline & Polydiaxone 1 & 22 & 10 & 2 & 10 \\
\hline & Polyglactin $2 / 0$ & 17 & 6 & 8 & 3 \\
\hline & Polyamide Polymer 1 & 6 & 0 & 3 & 3 \\
\hline \multirow[t]{2}{*}{ Mastectomy } & Number of Procedures & 60 & 20 & 20 & 20 \\
\hline & Number of suture materials & 160 & 51 & 43 & 66 \\
\hline \multirow[t]{2}{*}{ Skin } & Polyglecaperone $3 / 0$ & 42 & 20 & 0 & 22 \\
\hline & Staples & 21 & 0 & 20 & 1 \\
\hline Fascia & Polyglactin $2 / 0$ & 81 & 28 & 14 & 39 \\
\hline \multirow[t]{2}{*}{ Drain } & Polyamide Polymer 1 & 10 & 0 & 6 & 4 \\
\hline & Silk & 6 & 3 & 3 & 0 \\
\hline \multirow[t]{7}{*}{ Appendicectomy } & Number of Procedures & 50 & 17 & 15 & 18 \\
\hline & Number of suture materials & 90 & 36 & 21 & 29 \\
\hline & Polyglactin $2 / 0$ & 34 & 17 & 6 & 11 \\
\hline & Polyglactin $3 / 0$ & 22 & 7 & 8 & 7 \\
\hline & Polydiaxone 1 & 9 & 2 & 0 & 3 \\
\hline & Polyglecaperone $3 / 0$ & 13 & 9 & 2 & 2 \\
\hline & Polyamide Polymer $3 / 0$ & 12 & 1 & 5 & 6 \\
\hline \multirow[t]{7}{*}{ Inguinal Hernia } & Number of Procedures & 33 & 14 & 11 & 8 \\
\hline & Number of suture materials & 86 & 47 & 21 & 18 \\
\hline & Polypropylene $2 / 0$ & 26 & 11 & 7 & 8 \\
\hline & Polypropylene $3 / 0$ & 7 & 7 & 0 & 0 \\
\hline & Polydiaxone & 14 & 5 & 9 & 0 \\
\hline & Polyglactin $2 / 0$ & 21 & 16 & 2 & 3 \\
\hline & Polyglecaperone $3 / 0$ & 18 & 8 & 3 & 7 \\
\hline
\end{tabular}




\section{Statistical analysis}

Descriptive statistics were used in the analyses using SAS version 9.4. The qualitative information obtained from the financial departments was combined (by the investigators) to provide an evaluation of cost based on stock and procurement systems of each hospital.

\section{Results}

\section{Suture material usage}

A total of 203 datasheets detailing operative use of suture material were collected ( $85 \%$ response rate) with a $75 \%$ completion rate. The three hospitals contributed equally to the study with 71, 66 and 66 procedures from $\mathrm{H} 1, \mathrm{H} 2$ and $\mathrm{H} 3$, respectively. Suture material use for each procedure at each hospital is provided in Table 1.

\section{Abdominal wall closure}

A total of 60 abdominal wall closure procedures were included in the study. The majority of cases $(88.3 \%)$ were closed with PDS $^{\circledR}$ (Loop PDS and PDS1) and this was consistent across all three facilities (Table 1). With an average of 1.4 units per procedure.

\section{Mastectomy}

Sixty mastectomy procedures were included in the study. Standard superficial fascial closure in mastectomy at all hopitals was with Polyglactin $\left(\right.$ Vicryl $\left.^{\circledR}\right)$. H2 used staples for skin closure, H1 and H3 used Poliglecaprone (Monocryl ${ }^{\circledR}$ ). The average number of suture units per procedure was 3.35 and 3.80 in $\mathrm{H} 1$ and $\mathrm{H} 3$ respectively, with a lower average of 2.00 units at $\mathrm{H} 2$ due to staple use (Table 1).

\section{Appendicectomy}

Fifty appendicectomies were included in the study. Polyglactin $\left(\right.$ Vicryl $\left.{ }^{\circledR}\right)$ was the material of choice for ligation of the appendix in $82 \%$ of cases, the majority of which were ligated with Polyglactin $\left(V_{i c r y l}{ }^{\circledR}\right) 2 / 0$ or $3 / 0$. This was also the material of choice for closure of the sheath. Skin was closed with Poliglecaprone (Monocryl ${ }^{\circledR}$ ) in $40 \%$ of cases, Polyamide Polymer $\left(\right.$ Nylon $\left.^{\circledR}\right)$ in $28 \%$ of cases and Polyglactin rapid (Vicryl rapide ${ }^{\circledR}$ ) in $10 \%$ of cases. The average number of units of material used at all three hospitals was 2.42 units which was consistent between facilities.

\section{Inguinal hernia repair}

Data was only obtained on 33 of the 60 cases. At all 3 hospitals, in tissue and mesh procedures, Polypropolene $\left(\right.$ Prolene $\left.^{\circledR}\right)$ material was used for floor repair, Polyglactin $\left(\right.$ Vicryl $\left.^{\circledR}\right)$ for sheath repair and Poliglecaprone (Monocryl ${ }^{\circledR}$ ) for skin closure. For tissue repair, Polydiaxone $\left(\mathrm{PDS}^{\circledR}\right)$ was frequently used. On average of 3.61 units were used per case.

\section{Suture material performance and availability}

Of the 203 procedures, surgeons reported suture materials were either unavailable or broke on 53 occasions $(26 \%)$ (Table 2). The most common cited issue was lack of availability in $37(18 \%)$ cases with the preferred material being out of stock. Suture availability and performance was reported as adequate in appendectomy and inguinal hernia repair as opposed to abdominal wall closure and mastectomy. In abdominal wall closure, H1 mainly used a proprietary international product, while $\mathrm{H} 2$ and $\mathrm{H} 3$ mainly used a generic locally manufactured product; surgeons were not satisfied with the suture availability in $46.6 \%$ of all cases. The generic product was used in $67 \%$ of cases with $52 \%$ satisfaction compared to $33 \%$ usage with $73 \%$ satisfaction using the branded product $(\mathrm{P}$-value $=0.06)($ Table 2$)$. For mastectomy procedures, the generic product made up $52 \%$ of suture product used; H3 was the only facility which used proprietary material in the majority of cases. Intraoperative suture material breakages during these two procedures occurred with 16 units of material (7\%), six during abdominal wall closures and six during mastectomy, all occurred with generic suture use. In 3 procedures, more than one unit of material broke.

\section{Suture material procurement and cost}

This study found that there is no consistent electronic method of consolidation of suture stock information from the clinical level up to the procurement, stock control/receiving and finance departments in all three hospitals; each procurement and financial department categorised and ordered suture material differently. No individual suture material cost information was obtainable from any of the facilities. The stock management and costing system of each hospital is described below.

H1 operating theatres order suture materials directly from the Procurement Department; stock is delivered directly to theatre, with no handling in the Hospital Stores Department. The quantity of stock received is not recorded centrally, nor is its use. The Procurement Department orders stock on a monthly basis; no consolidation of annual volumes of individually ordered items is recorded. The finance department was able to supply annual suture material expenditure from 2011 to 2013; these were reported as R7 691 951.93, R14 287362.48 and R6 641681.29 respectively. In 2012, a debt previously contracted was included as paid which inflated the figure that year. It is not possible to determine the exact suture material usage and cost from these figures as they did not isolate for suture material alone, but rather broader surgical resource categories.

At $\mathrm{H} 2$, certain suture material stock is held as dry stock in the Stores Department and the theatre is able to order additional consumables in a 'buy out' (purchase and delivery of non-tender items). A 'buy out' is reserved for specialised consumable items which include most suture material types used in this study. Stock is delivered directly to the theatre. No electronic records are kept of volumes of suture materials used, ordered or received. The dry stores, which hold a minimum required volume of suture material, recorded items ordered, received and distributed. There is no information link between dry stock and theatre. The only readily available costs were R603 559.00 in 2011 and R272 638.00 in 2012. The cost of 'buy outs' was not available.

In $\mathrm{H} 3$, the theatre stores department is responsible for ordering suture material, an entirely paper based system. 
Table 2. Suture material performance and availability

\begin{tabular}{|c|c|c|c|c|c|c|}
\hline \multirow[t]{2}{*}{ Procedure } & \multirow[t]{2}{*}{ Suture Material } & \multicolumn{4}{|c|}{ Number of procedures \& suture material } & \multirow[t]{2}{*}{ P-value } \\
\hline & & Total & H 1 & $\mathbf{H 2}$ & H 3 & \\
\hline \multirow[t]{6}{*}{ Abdominal Wall Closure } & Number of Procedures & 60 & 20 & 20 & 20 & \\
\hline & Number of suture materials & 83 & 27 & 29 & 27 & \\
\hline & $\%$ use of Local brand & $67 \%$ & $15 \%$ & $90 \%$ & $95 \%$ & \\
\hline & $\%$ use of Proprietary brand & $33 \%$ & $75 \%$ & $10 \%$ & $10 \%$ & \\
\hline & Satisfied with availability & $47 \%$ & $75 \%$ & $25 \%$ & $50 \%$ & 0.06 \\
\hline & Breakages & $7 \%$ & 0 & 0 & $22 \%$ & \\
\hline \multirow[t]{6}{*}{ Mastectomy } & Number of Procedures & 60 & 20 & 20 & 20 & \\
\hline & Number of suture materials & 160 & 51 & 43 & 66 & \\
\hline & $\%$ use of Local brand & $52 \%$ & $50 \%$ & $80 \%$ & $25 \%$ & \\
\hline & $\%$ use of Proprietary brand & $48 \%$ & $50 \%$ & $20 \%$ & $75 \%$ & \\
\hline & Satisfied with availability and performance & $88 \%$ & $75 \%$ & $85 \%$ & $75 \%$ & \\
\hline & Breakages & $4 \%$ & 0 & $4 \%$ & $6 \%$ & \\
\hline \multirow[t]{7}{*}{ Appendicectomy } & Number of Procedures & 50 & 17 & 15 & 18 & \\
\hline & Number of suture materials & 90 & 36 & 21 & 29 & \\
\hline & $\%$ use of Local brand & $54 \%$ & $44 \%$ & $80 \%$ & $41 \%$ & \\
\hline & $\%$ use of Proprietary brand & $26 \%$ & $39 \%$ & $13 \%$ & $18 \%$ & \\
\hline & $\%$ use of Unknown Brand & $20 \%$ & $17 \%$ & $7 \%$ & $41 \%$ & \\
\hline & Satisfied with availability and performance & $90 \%$ & $89 \%$ & $80 \%$ & $88 \%$ & \\
\hline & Breakages & 0 & 0 & 0 & 0 & \\
\hline \multirow[t]{7}{*}{ Inguinal Hernia } & Number of Procedures & 33 & 14 & 11 & 8 & \\
\hline & Number of suture materials & 86 & 47 & 21 & 18 & \\
\hline & $\%$ use of Local brand & $59 \%$ & $26 \%$ & $99 \%$ & $63 \%$ & \\
\hline & $\%$ use of Proprietary brand & $32 \%$ & $74 \%$ & $0 \%$ & $12 \%$ & \\
\hline & $\%$ use Unknown brand & $9 \%$ & $0 \%$ & $1 \%$ & $25 \%$ & \\
\hline & Satisfied with availability and performance & $88 \%$ & $44 \%$ & $18 \%$ & $26 \%$ & \\
\hline & Breakages & 0 & 0 & 0 & 0 & \\
\hline
\end{tabular}

Orders are placed and processed in the Theatre Complex store room and forwarded to the Procurement Department. Once the ordered stock arrives it is registered but not itemised at Main Stores and subsequently delivered to the Theatre Stores. There is no electronic record of residual stock or rate of suture use in the theatre stores department. Suture material costs are not available for individual items in the study years. For H3 the suture material expenditure for 2012 and 2013 was R9 097308 and R15 744915 respectively; these figures include debt roll overs. Actual suture material cost could not be determined.

\section{Discussion}

This study investigated suture material use, cost and procurement systems as an example of how consumables are used and ordered in three Gauteng academic hospitals. Our findings demonstrate that during the study period there was consistent use of suture type and unit volume; there were concerns of quality and handling of generic materials; and suture material procurement inefficiencies exist.
Surgeon dissatisfaction was greater with the generic brand material compared to the propriety brand (Table 1) in abdominal wall closure. Technical concerns related to quality of material are clinically relevant as implications of use of defective material for abdominal sheath closure include abdominal sheath dehiscence which has a $34-44 \%$ mortality rate $^{11}$ and dehiscence results in an incisional hernia rate of 40 $60 \%{ }^{10}$ with its own morbidities. In 2012, approximately 11500 general surgical procedures were performed at the three study sites: 3500 in H1, 1500 in $\mathrm{H} 2$ and 6500 in H3. Hospital costs following prolonged hospitalisation and long term economic and quality of life implications for the patient are further considerations that may outweigh cost discrepancies between branded and generic materials. In the literature, evidence based clinical protocols and organisational structures have been identified as core requirements of successful health care systems. ${ }^{12}$ Despite paucity of data of cost structures from this study; evaluation of suture use provides data to define suture type and quantity for procedural protocols and identifies concerns with generic branded material (Table 2). Further research is required to determine the long-term morbidities of generic brand suture use. 
Impaired flow of information, either as feedback or feedforward, is a key feature of dysfunctional healthcare organisations. Partial systems and executive dissociation further hinder processes designed to enable efficient health care, ${ }^{13}$ as well as fracturing organisations into independent components instead of functioning as a 'whole'. ${ }^{14}$ All of these problems are illustrated by the three procurement case studies.

In the 2012 financial year, the National Department of Health budget was R125.2 billion; the budget for all medical supplies (consumable materials) was R112.4 million. ${ }^{15-16}$ The cost of suture material ordered in 2012 by the three study hospitals was R23 $657308,21 \%$ of the national budget. International literature documents average surgical consumable expenditure of $2 \%$ of national health budgets. ${ }^{17,18}$ The appropriate allocation and use of financial budgets can only be achieved through meticulous processes that control the recording of stock use and ordering. These currently do not exist within the study hospitals. This study has limitations as there was a paucity of cost and procurement data due to the lack of electronic platforms and standardised stock processes in all three study hospitals and therefore cost is not attained. This study was further limited by evaluation of three facilities in one province and thus not representative of national structures.

\section{Conclusion}

This study has identified inefficiencies in the public health care sector by using suture material use and its procurement as an audit of commonly used consumable materials. The clinical implications of generic brand suture use should be investigated to determine whether or not there is a long-term patient and cost benefit compared to original branded suture material. Furthermore, there is a lack of communication between the clinical, financial management, procurement officers, hospital and theatre stores in this surgical system. Protocols and systembased strategies should be put in place to manage surgical consumables, ultimately to enable safe and cost-effective clinical practice.

\section{REFERENCES}

1. Lohr KN, editor. Medicare: A strategy for quality assurance. Vol I and II. Washington DC: National Academy Press, 1990.

2. Clarke DL, Kong VY, Handley J, Aldous C. A concept paper: Using outcomes of common surgical conditions as quality metrics to benchmark district surgical services in South Africa as a part of a systematic quality improvement programme. S Afr J Surg. 2013;51(3):84-6. doi: 10.7196/SAJS.1476. PMID 23941751

3. The Lancet Commission on Global Surgery. Global surgery 2030. Accessed on 31 July 2016. Available from: http://media.wix.com/ ugd/346076_713dd3f8bb594739810d84c192 8ef61a.pdf

4. World Health Organisation. WHO guidelines for safe surgery 2009.
Accessed on 31 July 2016. Available from: http://apps.who.int/iris/ bitstream/10665/44185/1/9789241598552_eng.pdf

5. Lai S. Medscape Sutures and Needles. Accessed on 31 July 2016. Available at: http://emedicine.medscape.com/article/884838overview\#a30

6. Diener M, Voss S, Jensen K, Büchler M, Seiler C. Elective Midline Laparotomy Closure: The INLINE Systematic Review and Meta-Analysis Annals of Surgery: May 2010;251(5):843-56. doi: 10.1097/SLA.0b013e3181d973e4. PMID 20395846

7. Seiler CM, et al. Interrupted or continuous slowly absorbable sutures for closure of primary elective midline abdominal incisions: a multicenter randomized trial (INSECT: ISRCTN24023541). Ann Surg. April 2009;249(4): 576-82.doi: 10.1097/SLA. 0b013e31819ec6c8. PMID 19300233.

8. Greenberg J, Clark R. Advances in Suture Material for Obstetric and Gynaecologic surgery Rev Obstet Gynaecol. 2009;2(3):14658. PMCID: PMC 2760901.

9. Kruger D, Veller MG. Exposure to key surgical procedures during specialist general surgical training in South Africa. S Afr J Surg. 2014;52(4):96-100. doi:10.7196/SAJS.2162

10. Hodgson NC, Malthaner RA, Ostbye T. The search for an ideal method of abdominal fascial closure: a meta- analysis. Ann Surg. March 2000;231(3):436-42.

11. Mizell J. Complications of abdominal surgical incisions. In Up To Date. Accessed on 31 July 2016. Available from: http://www. uptodate.com/contents/complications-of-abdominal-surgicalincisions? source $=$ search_result\&search $=$ Complications + of + abdominal + surgical + incisions $\&$ selectedTitle $=1 \% 7 \mathrm{E} 150 \&$ view $=$ outline.

12. Suter E, Oelke N, Adair C, Armitage G. Ten Key Principles for Successful Health Systems Integration Journal of Healthcare Quality. Oct 2009;13(Spec No):16-23. PMCID: 3004930.

13. Yank G. Quality improvement in health care organizations: A general systems perspective. Behavioural Science. 1995;40(2):8599. PMID:7726814.

14. Sirgy MJ. Toward a theory of social organization; a systems approach. Behavioural Science 1989;34:272-85. doi: 10.1002/ bs.3830340404

15. National Treasury Republic of South Africa. Estimates of National expenditure 2015. Accessed on 31 July 2016. Available from: http://www.treasury.gov.za/documents/national\%20budget/2015/ ene/FullENE.pdf.

16. Gauteng Provincial Government. Gauteng health turnaround strategy 2014. Accessed on 31 July 2016. Available from: http:// www.health.gpg.gov.za/dohDocuments/Turnaround\%20Strategy/ GAUTENG\%20HEALTH\%20STRAT\%20TURNAROUND.pdf

17. Canadian Institute for Health Information. Hospital Trends in Canada - Results of a Project to Create a Historical Series of Statistical and Financial Data for Canadian Hospitals Over Twenty-Seven Years, 2005. Accessed on 27 August 2011. Available from: https://secure.cihi.ca/free_products/Hospital_Trends_in Canada_e.pdf

18. National Audit Office UK. The procurement of consumables by NHS acute and foundation trusts, 2011. Accessed on 31 July 2016. Available from: https://www.nao.org.uk/wp-content/ uploads/2011/02/1011705.pdf 